Article

\title{
The Effect of Financial Anxiety on the Insurance Behavior of Russian Citizens in the Context of the 2019-nCoV Pandemic
}

\author{
Olga Medyanik \\ Department of Political Psychology, St. Petersburg state University, \\ Nab. Makarova, H. 6, Saint-Petersburg, 199034, Russia; \\ medyanikov@list.ru or o.medyanik@spbu.ru; Tel.: +7-(812)-324-25-74 or +790-520-252-11
}

\begin{abstract}
In the context of the economic and political uncertainty associated with the 2019-nCoV pandemic, it is necessary to determine the socio-psychological factors involved in the transformation of the behavior of insurance consumers under the influence of a biogenic threat. This study measures financial anxiety and its impact on the insurance behavior of Russian citizens. The correlation, comparative, and regression analyses of the financial anxiety of Russian citizens cover three stages of observation: before the start of the $2019 \mathrm{nCoV}$ pandemic ("FA up to $19 \mathrm{nCoV}$; $\mathrm{N}=766$ ), during the period of quarantine measures announced in Russia in March 2020 ("FA 19-nCoV-1"; $\mathrm{N}=856$ ), and after the relaxation of quarantine measures at the end of April 2020 ("FA 19-nCoV-2"; $N$ = 963).Psychological analysis data were obtained from the online survey "Financial anxiety (in the context of insurance)". The questionnaire is psychometrically reliable and easy to use. It includes five measurement scales: MR1-Physical manifestations of financial incentive anxiety, MR2-With money shortages and financial uncertainty, MR3-The value of insurance coverage, MP4-Financial Confidence, and MR5-Perception of insurance and investment risks. It was found that Russian citizens consider it important to have insurance coverage for a "rainy day", and they showed confidence in the insurance market during the biogenic crisis. However, unfortunately, during the $19-\mathrm{nCoV}-1$ and $19-\mathrm{nCoV}-2$ periods, Russian citizens did not feel financially secure, unlike in the period before $19-\mathrm{nCoV}$. Women showed high scores for physical manifestations of financial anxiety and low financial confidence in the future, in contrast to men, regardless of the observation period.
\end{abstract}

Keywords: financial anxiety; insurance behavior; economic security of the person; financial confidence after COVID-19

\section{Introduction}

Today, humanity has experienced an unprecedented fear of bio-threat, in the form of a severe acute respiratory infection caused by the SARS-CoV-2 coronavirus (2019-nCoV) [1]. We can assume that this fear is worse than the fear of war or terrorist attacks, because as it turns out, the bio-threat can reach any part of the Earth in a short time. Health, manufacturing, agriculture, education, transportation, travel, sports, and fashion will be revolutionized as a result of this pandemic [2]. Any encounter with the unknown causes an alarming state of the population, especially in the economic field. The psychological community undoubtedly needs to build up knowledge on the new challenge of the 2019-nCoV pandemic.

Research on financial anxiety about financial and insurance decisions is not a new area of research. However, in the context of the economic and political uncertainty associated with the nCoV 2019 pandemic, it is necessary to monitor the dynamics of the main indicators of the Russian insurance market as well as its product and demographic structure during the period preceding the 
onset of the pandemic and to determine the factors transforming the behavior of insurance consumers under the influence of the biogenic threat.

Recently, more and more researchers and practitioners at the Russian and international levels have been paying attention to the need to actively investigate issues of personal economic security in the field of insurance policy. The urgency of preventing threats in the period of political, economic, and new threat-biogenic crises to the economic security of individuals that may cause economic and psychological damage is obvious.

We highlight the main external threats to economic activity: increased social and economic stratification, distrust of financial institutions and lack of confidence in the future, preservation of solvency, disruption to planning of future investments, and employment insecurity and the risk of property loss. Most of these threats can be covered by an insurance institute.

Preparation for this study focused on developing a theoretical understanding of economic security issues, as exemplified by the insurance industry. The literature review of our study was based on important determinants that influence consumer attitudes towards insurance during a crisis, including physical manifestations of concern about financial incentives, the value of insurance coverage, perceptions of insurance risks, experience of lacking money and financial uncertainty, and financial confidence (optimism).

\section{Literary Review}

\subsection{Financial Anxiety}

In this study, we do not dwell on the different definitions of anxiety associated with different types of stressful situations. We pay attention only to those states of anxiety that are associated with financial incentives, such as caring for the financial future, maintaining financial stability, etc. Financial stress is a subjective response to economic difficulties. Among the alarming levels of stress experienced by citizens, the most frequently cited financial stressors are fears of having enough money and job security and preserving personal investments and assets.

This study took into account the scientific contributions of many researchers who have studied financial anxiety in different ways. K. Gill and JB Brendan [3] showed that financial anxiety is a separate construct from depression and general anxiety. In their study of financial anxiety [3], respondents who reported having financial anxiety showed a latent response when processing financial information. The results of a clinical trial conducted by Grable, Heo, and Rabbani [4] showed that financial anxiety is a painful attitude towards a person's financial situation, in which psycho physiological arousal or a physical precursor of behavior plays an important role in shaping the consumer's intention to participate in future financial planning. The results of their research showed that those who use financial advisor services most frequently have low levels of financial anxiety and moderate to high levels of physiological arousal. Consumers who were reluctant to seek help from a financial advisor showed high levels of financial anxiety and low psycho physiological arousal. To encourage those with financial anxiety to make decisions, financial advisors must take specific steps to both reduce financial stressors and stimulate the initiation of financial incentives, thereby influencing consumer decisions.

In the context of our research, it is important to note the work of Johnson and Peterson [5]. The aim of their study was to examine how small-1 and medium-sized regional financial service firms responded to the 2008 financial crisis by helping their clients cope with increased financial anxiety in a crisis. The survey results highlighted the desire of many retail financial institutions to rethink their customer relationships in the aftermath of the financial crisis to help customers reduce consumer fears and financial anxiety, as the practical impact of the financial crisis in 2008 was significant changes in consumer attitudes towards financial service, leading to a decline in financial institutions and growing concern about financial risk.

\subsection{Insurance Relevance}


Overall, our review of previous research on insurance opportunities was based on an analysis of the vulnerability of consumers who fear for their personal property, finances, jobs, life, and health in an uncertain future. Making a decision to buy an insurance policy is a process consisting of various stages of decision making, ranging from understanding the need to shift insurance risk onto agents of the insurance market and ending with the formation of insurance trust for the entire term of the insurance policy. Making an insurance decision is an inter temporal choice that involves an awareness of the consequences of financial uncertainty. Remuneration for the possession of a product (insurance policy) in the future at some point is exchanged for full or partial cash repayment of all insured events. Making the decision to buy an insurance policy changes a consumer's lifestyle, and an insurance culture is acquired.

Financial, political, and biogenic crises can affect consumer financial behavior in different ways, depending on gender, age, and other characteristics. According to a study by Garling, Kirchler, and Lewis [6] devoted to decision-making in the context of the 2008 financial crisis, young people are more flexible than older people. However, older people who have experienced economic downturns in the past do better than younger people who lack such experience. Pessimistic people and people from lower socioeconomic backgrounds adapt by buying less, while optimistic people and people from higher socioeconomic backgrounds continue their consumption and lifestyles by purchasing higher quality products with a longer shelf life.

In general, our review of previous research on the feasibility of insurance was based on an analysis of the vulnerability of consumers who are worried about their personal property, finances, work, life, and health during conditions involving an uncertain future. Making a decision to purchase an insurance policy is a process consisting of various stages of decision-making, starting from understanding the need to shift the insurance risk to agents of the insurance market and ending with the formation of insurance confidence for the entire term of the insurance policy. Making an insurance decision is an inter temporal choice that involves an awareness of the consequences of financial uncertainty. Remuneration for the possession of the product (insurance policy) in the future at some point is exchanged for full or partial monetary repayment of all insurance claims. Making a decision to purchase an insurance policy changes the consumer's lifestyle, and an insurance culture is acquired.

\subsection{Perception of Insurance Risk}

Business operators assess the future consequences of their level of financial risk. Long-term monitoring of policyholders (2008-2016) and an empirical study of the attitude of the population of Russia to insurance policies (2019) [7] showed that citizens are divided into three psycho types: "supporter of market economy", "paternalists", and "neutrals". Paternalistic citizens, who often work in the public sector, are less trusting of insurance institutions, considering it inappropriate to transfer their property and non-property risks to the shoulders of enterprises, insurance companies, and other agents of the insurance market. They believe that the state should be responsible for all insurance contingencies and prefer to limit their consumption by buying only compulsory insurance programs, such as MTPL. The next category of citizens, which tends to involve individuals who work in the commercial sector and have an average income, approve the market policy of the state and participate in the consumption of insurance products, including voluntary types of insurance, approving the transfer of insurance risk to the agents of the insurance market."Neutrals" are those consumers who clearly do not trust market institutions, but also do not see the importance of the role of the state.

A consumer's attitude to risk is both an obstacle and an advantage in the decision-making process. Previous studies by Stroe Mihaela Andreea and Iliescu Mihaela [8] found that there are gender differences in risk perception in insurance decision making. Women are more likely to take risks than men and less likely to transfer risk to an insurance business. There are also differences in insurance risk taking, overconfidence, and information handling. It is possible that attitudes are shaped by positive or negative personal experiences and other psychological factors in addition to the impact of marketing on consumers. 


\subsection{Lack of Money and Financial Uncertainty}

The problem of consumer experience with money deficit was most fully disclosed in the work of Gasiorowska [9] in 2014 on the relationship between objective and subjective perceptions of wealth, which are mediated by financial control and financial anxiety.

From the point of view of an interdisciplinary approach, the American scientists Chow, Parmar, and Galinsky studied the problem of financial uncertainty [10].The effects of a series of five measures of physical pain on financial incentives showed a link between economic instability due to personal unemployment and general unemployment in the respondents' area and physical pain. A meta-analysis including all studies was done to test the link between economic instability and physical pain, and it was shown that the link is reliable. Researchers have defined economic instability as a state of uncertainty and an inability to control one's financial well-being. Economic instability can manifest itself both concretely (for example, as unemployment) and abstractly (for example, as the possibility of future layoffs).

Studies by other American authors have shown that economic instability can cause disaster. For example, this can lead to impaired cognitive function [11], impaired self-esteem [12], and unproductive financial planning [12].Thus, economic instability affects human behavior and psychological well-being. Financial control and financial stability are key factors in physical and mental well-being [13].

In developing our study, we relied, from our point of view, on very high quality empirical material from recent studies of financial anxiety conducted by Burchell and Shapiro (2012) [14], financial anxiety, physiological anxiety, and financial planning by Grable (2014) [15],the relationship between financial anxiety and the use of credit cards by Barbosa, Smith, and Boubacar (2016) [16], and creditworthiness and financial well-being by Hughes et al. (2019) [17].

\subsection{Financial Confidence}

Research papers on financial confidence can be found in both Russian literature and from Western sources. We were interested in researching financial confidence in the context of insurance protection. Here, the financial confidence of policyholders acts as a level of insurance trust in the system. Regression analysis of data from our previous surveys showed that respondents who are classified as "actual policyholders" and "supporter of market economy" are more likely to prefer voluntary insurance programs. Thus, the likelihood of citizens having a positive attitude about their insurance policy will be higher for citizens who already have experience in the insurance sector and citizens who work in the commercial sector of the economy and use rational and market strategies to guide their economic behavior [7].

Financial and insurance literacy, economic education, and experience in finance and insurance are critical in this case. Similar results were obtained by other authors in the study of financial literacy and financial behavior, as follows: in an assessment of knowledge and confidence by Colleen [18] and a study on the spread of financial literacy to insurance literacy by Lin, Brune, and William [19].

\section{Materials and Methods}

The data used in this study were obtained as a result of the online survey "Financial anxiety (in the context of insurance)" [20], hereinafter referred to as the FA (insurance) questionnaire, which was conducted on three samples of Russian citizens.

The FA (insurance) questionnaire is a psychometrically reliable and easily implemented tool that has been used to assess the psychological state of citizens before and during the acute phase and the mitigation phase of isolation measures during the 2019-nCoV pandemic. It includes five measurement scales: MR1-Financial incentives, MR2-With money shortages and financial uncertainty, MR3-The value of insurance coverage, MP4-Financial Confidence, and MR5-Perception of insurance and investment risks. The ability to maintain positive emotions and the ability to recover from negative emotions (resilience) show the degree of variability in the 
emotional health and psychological state of citizens during a crisis. The questions were selected by taking into account the accentuated mental behavior associated with problems that a person may face during an economic crisis, including perceptions of insurance and investment risks. The method used in this study was a large-scale multifactorial questionnaire containing statements that can be used to express the degree of agreement (disagreement) on a 7-point Likert scale, where "7" means "strongly agree", and "1" means "absolutely disagree." Many statements about the scale of physical manifestations of financial anxiety (MR1)took into account the classification of mental and behavioral disorders (ICD-10) [21]. The introduction of the second scale, MR3-the value of insurance coverage, into the questionnaire is justified by the need to consider economic policy as the background of trust for insurance policies in general. The MR4 scale, financial confidence, measures the expectations of citizens regarding future financial prospects for them and their families. The scale measures the cognitive assessment of the correspondence of life circumstances to the expectations of a person and reflects a general measure of inner harmony and psychological satisfaction. The MR2 scale, experiencing a shortage of money and financial uncertainty, assesses the current financial condition of a citizen and subjectively assesses their financial situation during the crisis. The fifth scale, MR5-experience of insurance and investment risks, assesses the subjective state of a citizen's personal safety in relation to preventing risks and finding personal strategies for adapting to the 2019-nCoV pandemic.

To prepare a research program to determine the socio-psychological factors involved in the transformation of consumer behavior related to insurance products and services under the influence of the biogenic threat caused by the 2019-nCoV pandemic, we used the results of a longitudinal study involving the observation method and semi-structured interviews and empirical studies of the population's attitude to insurance during the period 2008-2019in Russia [20].

When interpreting statistical data on the dynamics of the insurance market, we took into account previous psychological measurements of the population obtained in our study [20].

The aim of our study was to study the manifestations of financial anxiety and the characteristics of insurance and financial behavior of Russian citizens in different periods: up to 2019-nCoV pandemic, the acute phase of the crisis, and at the end of quarantine measures. Our tasks included carrying out three waves of measurements on Russian citizens using the FA (insurance) questionnaire: a correlation analysis of data from each survey, a comparative analysis of survey data from different periods, and a regression analysis of all observations.

The survey was published on the SurveyMonkey Internet platform [22].The results were processed using the equipment of the resource center of SPbSU Science Park "Sociological and Internet Research" [https://researchpark.spbu.ru/rcsoc-rus].

\subsection{Approximate Characteristics of the First Wave of Measurements}

The first sample was surveyed on 03/09/2020 (before the start of the SARS-CoV-2 pandemic, "FA up to 19-nCoV"), and it involved 766 respondents (375 men, 391 women).Most of this sample were citizens aged $26-45$ (65\%), who subjectively defined their income as average $(57.31 \%)$. A proportion of $42.69 \%$ worked in the commercial sector, $14.36 \%$ worked in the public sector, and the rest were students(11.3\%), pensioners $(5.05 \%)$, or temporarily unemployed $(26.78 \%)$. Also, the majority $(67.78 \%)$ did not have an economic education (college, university, courses). The date of the survey,03/09/2020 (up to 19-nCoV),before the announcement of the pandemic was a period of relative economic stability in Russia before the onset of the biogenic crisis of $19-\mathrm{nCoV}$.

\subsection{Approximate Characteristics of the Second Wave of Measurements}

The second survey was conducted on 3/30/2020 during the active phase of the SARS-CoV-2 pandemic, after which the "1-FA 19-nCoV" survey was conducted. The date of the survey on 30 March 2020 coincided with the announcement of the following Decree of the Chief State Sanitary Doctor of the Russian Federation of March 30, 2020 N 9:"On additional measures to prevent the spread of COVID-2019" (as amended) [23]. This meant that the citizens of Russia could not continue to work and had to isolate themselves. The second group consisted of Russian citizens (856 
respondents) -400 men and 456 women. Most of this sample were also citizens aged 26-45 years $(62.70 \%)$, who subjectively defined their income as average (54.38\%). A proportion of $38.42 \%$ worked in the commercial sector, $12.46 \%$ in the public sector, and the rest were students $(11.3 \%)$, pensioners $(4.19 \%)$,or temporarily unemployed $(32.01 \%)$. Also, most $(65.12 \%)$ had no economic education (college, university, courses).The main interest of this study, which was conducted on 30March 2019, was to investigate the dynamics of financial anxiety during the period involving acute experience of quarantine measures and self-isolation in Russia (2019-nCoV). A new variable was included in the survey - whether the respondents had undergone courses in economic education and financial literacy. Those with higher financial literacy were expected to have a keener sense of anxiety about their financial future.

\subsection{Characteristics of the Third Wave Sample}

The third sample, which involved the investigation of the level of financial anxiety on 17 May 2020 during the end of the acute phase of the SARS-CoV-2 pandemic (hereinafter referred to as the "2-FA19-nCoV" survey) consisted of 963 Russian citizens. The poll date, 05/17/2020, was not chosen by chance. Information about a decrease in the incidence of 2019-nCoV in Russia and preliminary data on the lifting of quarantine measures in different regions of Russia began to appear in the media. Thus, financial anxiety was measured during the period of the easing of quarantine measures in Russia. The sample was heterogeneous -422 men and 538 women. Most of the individuals in this sample were also citizens aged 26-45 years old (58\%) who worked in the commercial sector $(32 \%)$.We introduced a new variable to determine the employment status of respondents - the loss of jobs during the period of self-destruction measures announced by the Russian leadership during the SARS-CoV-2 pandemic. Such citizens accounted for $19 \%$ of all respondents. Another new variable was also introduced-preferences regarding the consumption of insurance products. Most of the respondents identified the insurance purchases under compulsory programs (OSAGO) as being their priority $(47 \%)$, while $29 \%$ identified travel insurance and $11 \%$ identified mortgage insurance. A total of $25 \%$ of respondents had no experience in insurance consumption and about 15-20\% of citizens acquired voluntary types of insurance, such as VMI, CASCO, and real estate insurance (apartments, houses).

\subsection{Setting up Hypotheses}

Demographic variables served as indicative elements that acted as independent variables in our analysis. These predicates allowed us to take into account possible differences in the Russian sample in terms of age, sex, employment, and accessibility of economic education and choice in the consumption of insurance programs. Several of these variables were identified in the literature review as potentially important factors influencing levels and differences in financial literacy and financial behavior patterns.

Hypothesis 1 (H1). Our hypothetical expectation of the results was that empirical research data would demonstrate a positive relationship between respondents' financial anxiety and economic education status.

Hypothesis 2 (H2). Secondly, we predicted that insurance consumption would have a positive effect on reducing financial anxiety.

Hypothesis 3 (H3). With regard to gender differences, women are more likely to be physically anxious about material incentives and have a lower degree of financial confidence in the future.

Hypothesis 4 (H4). For the employment variable, we expected a positive correlation, indicating that the level of financial confidence during a pandemic would be lower for unemployed citizens and citizens who lost their jobs due to quarantine measures, in contrast to other categories of citizens.

Hypothesis 5 (H5). Finally, we predicted that active consumers of insurance services would feel confident in their financial future regardless of a period of stability or biogenic crisis.

\section{Results and Discussion}




\subsection{Correlation Analysis}

The correlation analysis of data from the three waves of measurement of financial anxiety of Russian citizens showed the following results.

\subsection{Gender Difference}

Significant gender differences were found in three factors: MR1, MR2, and MR3 (Table 1). This partially confirmed hypothesis H3: women have higher physical manifestations of anxiety on material incentive.

Table 1. Significant cross-group data on gender differences*.

\begin{tabular}{|c|c|c|c|c|c|c|}
\hline \multirow{3}{*}{ Factors } & \multicolumn{2}{|c|}{$\begin{array}{l}\text { FA up to19-nCoV } \\
\qquad N=766 \\
\end{array}$} & \multirow{2}{*}{\multicolumn{2}{|c|}{$\begin{array}{c}\text { 1-FA19-nCoV } \\
\mathrm{N}=856 \\
\text { Gender }\end{array}$}} & \multicolumn{2}{|c|}{$\begin{array}{l}\text { 2-FA 19-nCoV } \\
\qquad \mathrm{N}=963\end{array}$} \\
\hline & & & & & & \\
\hline & M & $\mathbf{w}$ & $\mathbf{m}$ & $\mathbf{w}$ & $\mathbf{m}$ & $\mathbf{w}$ \\
\hline $\begin{array}{l}\text { MR1. Physical manifestations of anxiety on } \\
\text { financial incentives }\end{array}$ & -0.16 & 0.13 & -0.23 & 0.14 & -0.23 & 0.18 \\
\hline $\begin{array}{c}\text { MR2. Experiencing money shortages and financial } \\
\text { uncertainty }\end{array}$ & -0.10 & 0.08 & -0.15 & 0.17 & -0.18 & 0.14 \\
\hline MR3. Value of insurance coverage & -0.12 & 0.11 & -0.14 & 0.09 & -0.14 & 0.11 \\
\hline MR4. Financial confidence & 0.01 & -0.01 & 0.08 & -0.08 & 0.67 & -0.05 \\
\hline MR5. Perceptions of insurance and investment risks & 0.07 & -0.13 & 0.03 & -0.06 & 0.10 & -0.08 \\
\hline
\end{tabular}

*Note: the table shows the average values of each category for each factor. We tested the differences between the categories of each variable within each factor. If there were only two categories, the Shapiro-Wilk test was used; if there were more categories, the Kruskal-Wallis pair wise test was used. The orange color indicates groups in which a statistically significant difference was found at $p=$ 0.05. For variables with categories greater than two, groups with a statistical difference are explained.

Regardless of the period in which the respondents lived, these differences were confirmed. However, men were found to be more sensitive than women to problems of money shortage and financial uncertainty (MR2), and they were shown to trust insurance institutions more. These data are consistent with the work of Stroe Mihaela Andreea and Iliescu Mihaela [8], who determined that there are gender differences in risk perception attitudes in the insurance decision-making process. Women are more likely to take risks than men and are less likely to transfer risk to insurance businesses. During the 1-19-nCoV and 2-19-nCoV periods, men showed greater confidence in the future than women (MR4). During the end of the acute phase of the SARS-CoV-2 pandemic, there were significant differences in the experience of insurance and investment risks(MR5). In the 2-19-nCoV period, men were more likely than women to agree that large purchases should be made on credit and were concerned that they might not be approved for a bank loan.

\subsection{Age Differences}

Significant age differences were only obtained for the MR5 factor (Table2). Experience with insurance risk and problems with lending in the period up to19-nCoV and in 2-19-nCoV was more often a characteristic of citizens aged 45-65 years old. Citizens aged 26-35 were less likely to make large purchases on credit, as opposed to those aged 36-45 (1-19-nCoV). In the 2-19-nCoV period, young citizens aged 18-25 were less concerned about bank loan approval and insurance risk than those aged 45-65.

Table 2. Significant inter-group data on age differences*.

\begin{tabular}{|c|c|c|c|c|c|c|c|c|c|c|c|c|}
\hline \multirow{3}{*}{ Factors } & \multicolumn{4}{|c|}{$\begin{array}{c}\text { FA up to19-nCoV } \\
N=766\end{array}$} & \multirow{2}{*}{\multicolumn{4}{|c|}{$\begin{array}{c}\text { 1-FA19-nCoV } \\
\text { N = 856 } \\
\text { Age }\end{array}$}} & \multicolumn{4}{|c|}{$\begin{array}{c}\text { 2-FA19-nCoV } \\
\mathrm{N}=963\end{array}$} \\
\hline & & & & & & & & & & & & \\
\hline & $18-25$ & $26-35$ & $36-45$ & $46-65$ & $18-25$ & $26-35$ & $36-45$ & $46-65$ & $18-25$ & 26-35 & $36-45$ & $46-65$ \\
\hline MR1 & 0.08 & 0.05 & -0.05 & -0.20 & 0.03 & 0.003 & -0.07 & -0.21 & 0.07 & 0.02 & -0.11 & -0.04 \\
\hline MR2 & -0.09 & 0.03 & 0.08 & -0.10 & -0.04 & 0.07 & 0.01 & -0.03 & -0.09 & 0.07 & 0.03 & -0.05 \\
\hline MR3 & -0.01 & -0.004 & -0.08 & 0.15 & 0.03 & -0.01 & -0.12 & 0.09 & 0.01 & 0.005 & -0.02 & -0.02 \\
\hline
\end{tabular}




\begin{tabular}{cccccccccccccc}
\hline MR4 & 0.03 & -0.09 & 0.07 & 0.001 & 0.05 & 0.01 & -0.05 & -0.10 & 0.07 & 0.02 & -0.07 & -0.06 \\
MR5 & -0.11 & -0.11 & 0.06 & 0.22 & -0.08 & -0.08 & 0.12 & 0.07 & -0.08 & -0.02 & 0.02 & 0.12 \\
\hline \multicolumn{1}{c}{ * see Note to Table 1.}
\end{tabular}

\subsection{Subjective Financial Status (Income)}

The following significant differences were obtained for the personal income variable (Table 3).

According to the MR1 factor: during the period up to $19-\mathrm{nCoV}$, physical manifestations of anxiety were shown by low-income citizens as opposed to middle-income citizens. In the 1-19-nCoV period, financial anxiety was not only higher for low-income citizens but also for very poor citizens.

Table 3. Significant inter-group differences in subjective income data*.

\begin{tabular}{|c|c|c|c|c|c|c|c|c|c|c|c|c|c|c|c|}
\hline \multirow[b]{2}{*}{ Factors } & \multicolumn{5}{|c|}{$\begin{array}{c}\text { FA up to } 19-\mathrm{nCoV} \\
\qquad \mathrm{N}=766\end{array}$} & \multicolumn{5}{|c|}{$\begin{array}{c}\text { 1-FA 19-nCoV } \\
\qquad \begin{array}{l}\mathrm{N}=856\end{array}\end{array}$} & \multicolumn{5}{|c|}{$\begin{array}{c}\text { 2-FA 19-nCoV } \\
\qquad \begin{array}{l}\mathrm{N}=963\end{array}\end{array}$} \\
\hline & $\begin{array}{l}\frac{3}{0} \\
\frac{2}{0} \\
0\end{array}$ & $\stackrel{3}{0}$ & 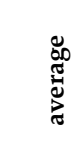 & 苑 & 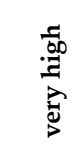 & $\frac{3}{0}$ & $\stackrel{3}{0}$ & 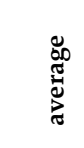 & $\begin{array}{l}\mathfrak{5} \\
.000 \\
3\end{array}$ & 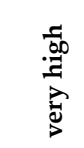 & $\begin{array}{l}3 \\
0 \\
0 \\
0 \\
0\end{array}$ & $\underline{3}$ & 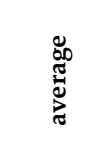 & 离 & 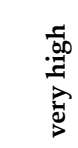 \\
\hline MR1 & 0.39 & 0.13 & -0.13 & -0.11 & 0.06 & 0.33 & 0.09 & -0.16 & 0.02 & 1.01 & 0.17 & 0.09 & -0.07 & 0.02 & 0.47 \\
\hline MR2 & 0.53 & 0.22 & -0.13 & -0.47 & -0.57 & 0.32 & 0.25 & -0.15 & -0.45 & -0.54 & 0.17 & 0.16 & -0.07 & -0.76 & -0.67 \\
\hline MR3 & -0.04 & -0.03 & 0.03 & 0.14 & -0.66 & -0.37 & -0.01 & 0.04 & -0.38 & -0.19 & -0.06 & -0.02 & 0.02 & 0.17 & -0.87 \\
\hline MR4 & -0.65 & -0.33 & 0.22 & 0.29 & 0.72 & -0.71 & -0.32 & 0.23 & 0.90 & 1.33 & -0.73 & -0.41 & 0.29 & 0.94 & 0.04 \\
\hline MR5 & -0.02 & -0.02 & -0.02 & -0.22 & 0.51 & 0.007 & 0.018 & -0.04 & 0.04 & 2.05 & -0.22 & 0.012 & 0.01 & 0.15 & -0.22 \\
\hline
\end{tabular}

Thus, the most financially unprotected group of the population (very low and low income individuals) demonstrated strong characteristics of anxiety, for example, "nausea and other discomfort in the stomach when I think about financial problems", "if I was cheated with money, my muscles contract and I can hardly breathe", and "when I have problems with money, my heart stops".

According to MR2, citizens who assessed their financial situation as low or very low were more concerned about problems regarding money deficit and debt relations in the periods up to $19-\mathrm{nCoV}$ and 1-19-nCoV.

For the MR3 factor, no significant differences were found. The level of consumer income did not affect the attitude to insurance for any of the three measures.

According to the MR4 factor, citizens with low or very low incomes were not sure about their financial future during the periods up to19-nCoV and 1-19-nCoV. In the post-crisis period, 2-19-nCoV, the financial confidence factor did not show significant differences within the sample.

According to the MR5 factor, in the 1-19-nCoVperiod, citizens with very high incomes were ready to borrow from the bank for large purchases. In the 2-19-nCoV period, low-and middle-income citizens were ready to take out loans from the bank, and they were at risk of losing their property, unlike citizens with very low incomes.

\subsection{Employment}

The analysis of data on the employment predictor gave the following results (Table 4). 
Table 4.Significant inter-group differences in employment data*

\begin{tabular}{|c|c|c|c|c|c|c|c|c|c|c|c|c|c|c|c|c|c|c|c|}
\hline \multirow[b]{2}{*}{ Factors } & \multicolumn{6}{|c|}{$\begin{array}{c}\text { FA Up to19-nCoV } \\
N=766\end{array}$} & \multicolumn{6}{|c|}{$\begin{array}{c}\text { 1-FA 19-nCoV } \\
\mathrm{N}=856\end{array}$} & \multicolumn{7}{|c|}{$\begin{array}{c}\text { 2-FA 19-nCoV } \\
\mathrm{N}=963\end{array}$} \\
\hline & 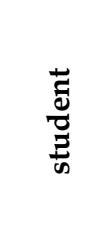 & 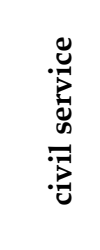 & 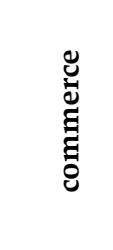 & $\frac{\mathscr{D}}{\frac{\mathscr{O}}{0}}$ & 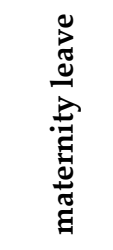 & 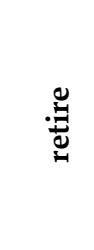 & 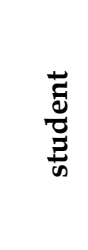 & 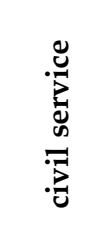 & 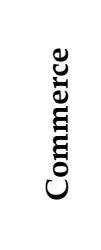 & $\begin{array}{l}\mathscr{0} \\
\stackrel{0}{0} \\
\stackrel{0}{0}\end{array}$ & 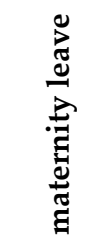 & : & $\begin{array}{l}\frac{\vec{E}}{0} \\
\frac{\tilde{D}}{\omega}\end{array}$ & 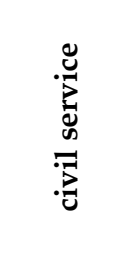 & 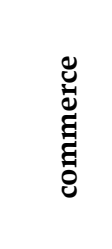 & $\begin{array}{l}\overline{8} \\
\ddot{0} \\
\frac{0}{0} \\
0\end{array}$ & $\begin{array}{l}z \\
0 \\
\dot{0} \\
\stackrel{1}{a} \\
0 \\
0 \\
\stackrel{0}{0} \\
\stackrel{0}{0}\end{array}$ & 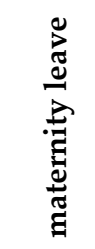 & 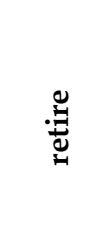 \\
\hline MR1 & 0.06 & 0.02 & -0.05 & -0.01 & 0.10 & -0.3 & 0.04 & -0.08 & -0.08 & 0.04 & 0.11 & -0.28 & 0.069 & 0.139 & -0.09 & 0.038 & 0.067 & 0.025 & -0.24 \\
\hline MR2 & -0.24 & 0.022 & -0.005 & 0.08 & 0.17 & -0.23 & -0.14 & -0.15 & 0.044 & 0.14 & 0.12 & -0.10 & -0.213 & -0.176 & 0.0047 & 0.14 & 0.14 & 0.16 & -0.33 \\
\hline MR3 & 0.14 & -0.02 & -0.058 & -0.10 & 0.14 & 0.20 & 0.03 & 0.33 & -0.11 & -0.10 & 0.10 & -0.15 & -0.03 & 0.02 & 0.05 & -0.10 & -0.03 & 0.02 & -0.01 \\
\hline MR4 & 0.07 & 0.05 & -0.013 & -0.19 & -0.03 & 0.32 & 0.15 & 0.20 & 0.05 & -0.33 & 0.003 & -0.063 & 0.12 & 0.34 & 0.11 & -0.26 & -0.32 & 0.04 & 0.01 \\
\hline MR5 & -0.2 & 0.07 & -0.007 & -0.027 & -0.015 & 0.23 & -0.06 & 0.17 & -0.08 & 0.05 & -0.02 & -0.02 & -0.11 & 0.11 & 0.03 & 0.03 & -0.03 & -0.08 & 0.02 \\
\hline
\end{tabular}


Regarding physical manifestations of financial anxiety (MR1), no significant differences were obtained depending on the type of employment.

For MR2 in the period "up to19-nCoV", unemployed people were more concerned about the lack of money in contrast to seniors; during the "19-nCoV-2" period,seniors showed less concern about the shortage of money than the unemployed and retired as a consequence of the pandemic and those on maternity leave.

According to the MR3 factor, during the acute phase of the pandemic, citizens working in the public sector gave increased importance to insurance protection than unemployed individuals and merchants.

For the MR4 factor, significant differences were obtained in the 1-19-nCoV and 2-19-nCoV periods. Public sector employees, students on maternity leave, and merchants showed greater financial confidence in the acute crisis phase of the pandemic than the unemployed. This can be explained by the specifics of the organization of state aid in Russia during the pandemic: citizens who were working informally or were unemployed were not organized by the state in any form. In the 2-19-nCoV period, financial insecurity was demonstrated by the unemployed and those who lost their jobs as a result of the pandemic crisis. Thus, hypothesis $H 4$ was confirmed.

\subsection{Education and Financial Literacy}

In measure 3, 1-FA19-nCoV, a new variable was introduced: the availability of economic education or financial literacy courses (Table 5). At a time of political and financial uncertainty, we expected that citizens with additional financial knowledge would respond more to the emergence of a crisis caused by a biogenic threat. Hypothesis H1 was confirmed: citizens with an economic education were more likely to give positive ratings on the scale of physical manifestations of financial anxiety.

Table 5.Significant cross-group differences in data depending on economic education or financial literacy *.

\begin{tabular}{lcccccc}
\hline & FA up to 19-nCoV & & 1-FA 19-nCoV & \multicolumn{2}{c}{ 2-FA 19-nCoV } \\
& $\mathbf{N}=766$ & $\mathbf{N}=856$ & & N = 963 \\
\hline Factors & & \multicolumn{7}{c}{ Economic Education } \\
& + & - & + & - & + & - \\
\hline MR1 & 0.052 & -0.046 & 0.054 & -0.074 & - & - \\
MR2 & 0.001 & -0.007 & 0.10 & -0.026 & - & - \\
MR3 & 0.008 & -0.015 & -0.06 & 0.01 & - & - \\
MR4 & 0.027 & -0.03 & -0.02 & 0.006 & - & - \\
MR5 & 0.05 & -0.06 & -0.02 & -0.01 & - & - \\
\hline \multicolumn{7}{c}{ * see Note to Table 1. }
\end{tabular}

\subsection{Consumption of Insurance Programs}

In the third measure, a new variable was introduced-preference for the consumption of insurance programs (Table 6). In this sample period, two months had passed since the introduction of quarantine measures. For the first time in modern history, Russian citizens faced the practice of self-isolation and special quarantine measures. How did the socio-economic situation affect the consumption of insurance products? An analysis of data from three measurements showed that Russian consumers who experienced greater physical manifestation of financial anxiety did not buy CTP for their car, in contrast to those who bought this program on a regular basis. We did not find any significant differences related to previous experience with money shortage, which means that there is no connection between buying insurance and experiencing money shortage. 
The relationship between the value of insurance protection and the consumption of insurance products was clearly demonstrated. Those consumers with higher ratings for the MR3 factor were more likely to use all the insurance programs listed in the survey in their household: mortgage, CTP, CASCO, VMI, NS, life and health, etc. These citizens can be considered "owners" of the insurance culture. This type of consumer is just beginning to appear in Russian society.

According to the MR4 factor, consumers who are confident in their financial future are more likely to buy almost all the programs listed in the survey, except for travel insurance and apartment and home insurance. The latter type is poorly represented in Russian insurance practice.

According to the MR5 factor, citizens who are experiencing insurance and investment risks are more likely to buy a hard hat for their car and accident insurance.

This confirmed the data from our previous studies [20]: active consumers of insurance services feel confident in their financial future. This confirmed hypothesis H5.

Table 6.Significant differences in data in group 3 (2-FA $19-\mathrm{nCoV} \mathrm{N}=963$ ) by preference for purchasing insurance programs *.

\begin{tabular}{|c|c|c|c|c|c|c|c|c|c|c|}
\hline \multicolumn{11}{|c|}{ (A) } \\
\hline \multirow{2}{*}{ Factors } & \multicolumn{2}{|c|}{ Mortgage } & \multicolumn{2}{|l|}{ OSAGO } & \multicolumn{2}{|c|}{ Tourism } & \multirow{2}{*}{$\begin{array}{c}\text { Real Estate } \\
-\end{array}$} & \multicolumn{3}{|c|}{ CASCO } \\
\hline & - & + & - & + & - & + & & + & - & + \\
\hline MR1 & -0.007 & 0.06 & 0.08 & -0.09 & -0.01 & 0.04 & -0.0003 & 0.001 & 0.01 & -0.04 \\
\hline MR2 & -0.01 & 0.09 & 0.01 & -0.01 & -0.01 & 0.05 & 0.02 & -0.10 & 0.01 & -0.05 \\
\hline MR3 & -0.02 & 0.22 & -0.10 & 0.11 & -0.09 & 0.25 & -0.06 & 0.30 & -0.09 & 0.41 \\
\hline MR4 & -0.027 & 0.22 & -0.05 & 0.06 & -0.01 & 0.04 & -0.01 & 0.07 & -0.02 & 0.11 \\
\hline MR5 & -0.01 & 0.11 & -0.03 & 0.03 & -0.001 & 0.002 & -0.008 & 0.04 & -0.02 & 0.11 \\
\hline \multicolumn{11}{|c|}{ (B) } \\
\hline \multirow{2}{*}{ Factors } & \multicolumn{2}{|c|}{ VHI } & Private Insurance & \multicolumn{3}{|c|}{ Life and Health Insurance } & \multicolumn{4}{|c|}{ No Experience } \\
\hline & - & + & - & + & & & + & & - & + \\
\hline MR1 & -0.008 & 0.04 & -0.001 & 0.03 & 0. & & -0.02 & & 003 & -0.001 \\
\hline MR2 & 0.01 & -0.08 & 0.002 & -0.03 & & & -0.07 & & 01 & -0.05 \\
\hline MR3 & -0.07 & 0.34 & -0.01 & 0.27 & -0 & & 0.34 & & 12 & -0.37 \\
\hline MR4 & -0.0260 & 0.126 & -0.02 & 0.39 & & & 0.147 & & 04 & -0.13 \\
\hline MR5 & -0.0168 & 0.0817 & -0.01 & 0.30 & & & 0.07 & & 01 & -0.05 \\
\hline
\end{tabular}

* see Note to Table 1.

\subsection{Comparative Analysis of Financial Anxiety Data from Three Waves of Measurement}

A comparative analysis of data from three measures of financial anxiety was performed (Table 7). The result of assessing the significance of insurance protection was unexpected. It was during the two-month economic and socio-psychological crisis that the demand for insurance protection grew, as opposed to in the period before the pandemic. Russian citizens considered it important to have insurance coverage for a "rainy day" and showed confidence in the insurance market. Additionally, as expected, significant differences financial confidence in the future were found: before the crisis associated with the 19-nCoV pandemic, Russian citizens felt more financially confident in the future than after experiencing the pandemic measures and the period of mitigation measures. Unfortunately, Russian citizens did not show confidence in the future after undergoing the quarantine measures.

Table 7.Comparative analysis of financial anxiety data from three waves of measurement

\begin{tabular}{lccc}
\hline & $\begin{array}{c}\text { FA Up to19-nCoV } \\
\mathbf{N = 7 6 6}\end{array}$ & $\begin{array}{c}\text { 1-FA 19-nCoV } \\
\mathbf{N = 8 5 6}\end{array}$ & $\begin{array}{c}\text { 2-FA 19-nCoV } \\
\mathbf{N = 9 6 3}\end{array}$ \\
\hline MR1 & -0.0656 & -0.0129 & 0.0275 \\
MR2 & -0.0169 & 0.00780 & 0.0198 \\
MR3 & -0.0791 & 0.0195 & 0.0355 \\
MR4 & 0.0762 & -0.0530 & -0.0242 \\
MR5 & -0.00230 & -0.0151 & -0.0140 \\
\hline
\end{tabular}

* see Note to Table 1. 


\subsection{Regression Analysis}

To determine the influences of independent variables (predictors), gender, age, financial status, and employment were analyzed for the" financial confidence factor" (Table 8). Significant indicators were only obtained for the financial confidence factor.

Table 8.Regression model of the "financial confidence factor" (all observations).

\begin{tabular}{|c|c|c|c|c|c|}
\hline & Variables & Coefficient & STD. Error & \multicolumn{2}{|c|}{$p$-Value } \\
\hline & Constant & 2.235 & 0.008 & $<2 \times 10^{-16}$ & $* * *$ \\
\hline gender & female & -0.010 & 0.003 & 0.001 & ** \\
\hline \multirow{4}{*}{$\begin{array}{l}\text { financial } \\
\text { situation }\end{array}$} & low & 0.034 & 0.006 & 0.000 & $* * *$ \\
\hline & average & 0.095 & 0.006 & $<2 \times 10^{-16}$ & $* * *$ \\
\hline & high & 0.141 & 0.012 & $<2 \times 10^{-16}$ & $* * *$ \\
\hline & very high & 0.133 & 0.022 & 0.000 & $* * *$ \\
\hline \multirow[t]{5}{*}{ employment } & civil service & 0.013 & 0.006 & 0.050 & * \\
\hline & commerce & 0.000 & 0.005 & 0.935 & \\
\hline & jobless & -0.014 & 0.006 & 0.014 & $*$ \\
\hline & retire & 0.017 & 0.008 & 0.043 & * \\
\hline & student & 0.009 & 0.007 & 0.146 & \\
\hline
\end{tabular}

Note: significance: $0^{\star * * * \prime}, 0.001^{\star * * \prime}, 0.01^{\text {‘’ }}, 0.05$.

Financial Confidence Factor

Women showed low values of financial confidence. Hypothesis H3 was completely confirmed: women, unlike men, are not only more susceptible to physical manifestations of financial anxiety but also have low financial confidence. Our research shows the stability of this psychological characteristic in all three studies, regardless of the crisis period faced by Russian women. In addition, low financial health was found to have an impact on financial confidence. This is an understandable fact, since citizens with medium and high financial statuses feel safe in their current situation and in the future. The pandemic crisis did not transform their sense of personal financial security. The regression analysis confirmed the partially correlated analysis of the employment predictor data: regardless of the pandemic crisis, citizens working in the public sector and pensioners were confident in their financial future. This is understandable, since these categories of citizens are guaranteed a minimum income from the state in the form of pensions or fixed wages. This is probably why Russian citizens often decide to work in the public sector, even though the salary is rather low.

\section{Conclusions}

In general, all the hypotheses put forward were statistically confirmed and were consistent with the conclusions of our other studies.

Improving the financial literacy of the population is key to encouraging them to make the right financial decisions while protecting consumers from financial anxiety. During difficult times, such as the COVID-19 pandemic crisis, the public look for ways to transfer financial risk to alternative instruments that could bring some financial independence and financial confidence in the future. As our research has shown, one of these institutions is the insurance sector of the economy. A well-designed financial information policy program should contribute to the development of insurance literacy and personnel management of external and internal risks. The development of an insurance culture in Russia should help consumers to understand the value of insurance.

It is expected that the results of this study may be useful to both the scientific community in the field of economic psychology and to industry practitioners. 
While this study has its advantages in terms of exploring new links between financial anxiety, financial confidence, insurance preferences, and experience with low-income demographics, there are some limitations to providing useful insights on the subject. However, the limitations of our study may serve as directions for future research for other work in this area. First, our questionnaire could be tested in different categories of insurance and financial services and the possible differences could be explored. Second, this study paves the way for future consumer insurance literacy researchers with regard to trust and favorable attitudes towards insurance.

Author Contributions: Conceptualization, O.M.; Methodology, O.M. Validation, O.M.; Formal Analysis, O.M.; Investigation, O.M.; Data Curation, O.M.; Writing, Review \& Editing, O.M.; Supervision, O.M.; Project Administration, SPBGU. All authors have read and agreed to the published version of the manuscript.

Funding: This research was funded by the author's personal funds under the initiative grant no. 106-16838 from the Saint Petersburg State University.

Acknowledgments: The author is grateful to the staff of the resource center of the SPBSU Science Park "Sociological and Internet research" for processing the results [https://researchpark.spbu.ru/rcsoc-rus] and Prof. Deyneka O.S.

Conflicts of Interest: The authors declare no conflict of interest.

\section{References}

1. Beeching, N.J.; Fletcher, T.E.; Fowler, R.Coronavirus disease 2019 (COVID-19): [apx. 18 anpess 2020]; BMJ Best Practices; BMJ Publishing Group: London, UK, 2020.

2. Samarathunga, W.; Weerathunga, P. Advent of 'Economic Paradigm Shift' and 5G during the $\begin{array}{llll}\text { Post-COVID19 Revival Phase. } & \text { Preprints. }\end{array}$ online:https://papers.ssrn.com/sol3/papers.cfm?abstract_id=3601484 (accessed on 07/30/2020).

3. Shapiro, G.K.; Burchell, B.J. Measuring financial anxiety. J. Neurosci. Psychol.Econ. 2012, 5, 92-103, doi:10.1037/a0027647.

4. Grable, J.; Heo, W.; Rabbani, A. Financial Anxiety, Physiological Arousal, and Planning Intention. J. Financ. Ther. 2015, 5, 2, doi:10.4148/1944-9771.1083.

5. Johnson, D.S.; Peterson, M.Consumer financial anxiety: US regional financial service firms' trust building response to the financial crisis. Int. J. Bank Mark.2014, 32, 515-533, doi:10.1108/IJBM-08-2013-0080.

6. Gärling,T.; Kirchler,E.; Lewis, A.; Raaij, V.F. Psychology, Financial Decision Making, and Financial Crises. Psychol. Sci. Public Interest 2009, 10, 1-47, doi:10.1177/1529100610378437.

7. Medyanik, O.; Deyneka, O. Russian Citizens' Attitude toward Insurance Policies as a Factor of Individual Economic Security. Behav. Sci.2020, 10, 23.doi:10.3390/bs10010023. ISSN: 2076-328X.

8. Andreea, S.M.; Mihaela, I. Attitudes and Perception in Consumer's Insurance Decision. Available online: http://nos.iem.ro/123456789/644 (accessed on 07/30/2020).

9. Gasiorowska, A. The relationship between objective and subjective wealth is moderated by financial control and mediated by money anxiety. J. Econ. Psychol.2014, 43,64-74,doi:10.1016/j.joep.2014.04.007.

10. Chou, E.Y.; Parmar, B.L.; Galinsky, A.D. Economic Insecurity Increases Physical Pain. Psychol. Sci. 2016, 27, 443-454, doi:10.1177/0956797615625640.

11. Heine, S.J.; Proulx, T.; Vohs, K.D. The meaning maintenance model: On the coherence of social motivations. Personal. Soc. Psychol. Rev. 2006, 10, 88-110, doi:10.1207/s15327957pspr1002_1.

12. Shah, A.K.; Mullainathan, S.; Shafir, E. Some Consequences of Having Too Little. Science2012, 338, 682-685, doi:10.1126/science.1222426.

13. Rodin, J.; Langer, E.J. Long-term effects of a control-relevant intervention with the institutionalized aged. J. Personal. Soc. Psychol. 1977, 35, 897-902, doi:10.1037/0022-3514.35.12.897.

14. Burchell, B. Measuring Financial Anxiety. J. Neurosci. Psychol. Econ. 2012, 5, 92.

15. Grable, J. Financial Anxiety, Physiological Arousal, and Planning Intention.J.Financ. Ther. 2014, 5. Available

online:https://www.academia.edu/25924785/Financial_Anxiety_Physiological_Arousal_and_Planning_Int ention (accessed on 07.30.2020).

16. Barboza, G.; Smith, C.; Boubacar, I.A Contribution to the empirics of consumers anxiety behavior on and in credit card repayment. Credit card management and financial literacy among college students. J. Financ. Manag. Mark. Inst. 2017, 35-66. doi: 10.12831/87059. 
17. Hughes, C.R. and all. The Impact of Credit-Worthiness on Financial Wellbeing, Anxiety, Depression, and Hopelessness. 2019. Available online: https://www.academia.edu/38648118/(accessed on 07.30.2020).

18. Colleen, T.A. Financial literacy and financial behavior: Assessing knowledge and confidence. Financial Services Review. Financ. Serv. Rev. 2015, 24, 101-117, 17p.

19. Lin, X.; Bruhn, A.; William, J. Extending financial literacy to insurance literacy: A survey approach. Account. Financ. 2019, 59, 685-713, doi:10.1111/acfi.12353.

20. Medyanik, O.V. Attitude of Citizens to Insurance Policy as a Factor of Economic Security of the Individual. Available online: https://disser.spbu.ru/files/2019/disser_medyanik.pdf (accessed on 29 January 2020).

21. The ICD-10 Classification of Mental and Behavioural Disorders. Available online: who.int>classifications/icd/en/bluebook.pdf(accessed on 07.30.2020).

22. Available online: https://ru.surveymonkey.com(accessed on 07.30.2020).

23. Resolution of the Chief State Sanitary Doctor of the Russian Federation of March 30, 2020 N 9 "on Additional Measures to Prevent the Spread of COVID-2019" (with Amendments and Additions).Available online: https://base.garant.ru/73824082/(accessed on 07.30.2020).

24. Sigma 4/2017: Insurance: adding value to development in emerging markets. https://www.swissre.com/institute/research/sigma-research/sigma-2017-04.html (accessed on 07.30.2020).

25. Deineka, O.S. Experience of Empirical Research of Political and Economic Consciousness; Series 16; Bulletin of Saint Petersburg University: Saint Petersburg, Russia; 2015; pp. 13-26. Available online:http://vestnik.spbu.ru/html15/s16/s16v3/s16v3.html(accessed on 07.30.2020).

26. Gangl, K.; Hofmann, E.; de Groot, M.; Antonides, G.; Goslinga, S.; Hartl, B.; Kirchler, E. Taxpayers' motivations relate to tax compliance: Evidence from two representative samples of Austrian and Dutch self-employed taxpayers. J. Tax Adm. 2015, 1, 15-25.

27. Gangl, K.; Pfabigan, D.; Lamm, C.; Kirchler, E.; Hofmann, E. Coercive and legitimate authority impact tax honesty. Evidence from behavioral and ERP experiments. Soc. Cogn. Affect. Neurosci.2017, 12, 1108-1117, doi:10.1093/scan/nsx029.

28. Gangl, K.; Torgler, B.; Kirchler, E. Patriotism's impact on cooperation with the state: An experimental study on tax compliance. Political Psychol. 2016, 37, 867-881.

29. Gąsiorowska, A. Hedonic treadmill. w: Real-World Decision Making. In An Encyclopedia of Behavioral Economics/Altman Morris (red.); Greenwood, ABC-Clio LLC: Santa Barbara, CA, USA, 2015; pp. 196-197, ISBN 978-1-4408-2815-7. 